\title{
Nacionalização da competição eleitoral no novo contexto democrático brasileiro: uma análise à luz das categorias analíticas do neoinstitucionalismo*
}

\author{
Nationalization of electoral competition in the new Brazilian democratic context: \\ a review in light of the analytical categories of new institutionalism
}

\begin{abstract}
Vítor Eduardo Veras de Sandes-Freitas
Bolsista da Fundação de Amparo à Pesquisa do Estado de São Paulo - FAPESP, Doutorando em Ciência Política, Universidade Estadual de Campinas - UNICAMP, e-mail: vitorsandes@yahoo.com.br
\end{abstract}

Recebido: 14/05/2012

Aceito: 11/09/2012
RESUmo Este artigo se propõe a analisar, a partir do aparato teórico do neoinstitucionalismo, o processo de nacionalização da competição eleitoral no Brasil, que tem levado à aproximação na forma como o Partido dos Trabalhadores (PT) e o Partido da Social Democracia Brasileira (PSDB) se articulam no âmbito nacional e estadual. PT e PSDB têm atuado como atores políticos fundamentais no processo de formação de coligações nos estados brasileiros, principalmente a partir do pleito de 1994, quando ambos passaram a concentrar a maior parte dos votos na disputa para a Presidência da República, conquistando também mais espaço político no nível estadual. Analisando a trajetória desse processo de atrelamento entre as dinâmicas estaduais e nacional, observa-se que este tem sido afetado por mecanismos de feedback positivo, gerando retornos crescentes (increasing returns) que reiteram e reforçam a existência do fenômeno. Esses mecanismos geram uma dependência de trajetória (path dependence) que dificulta aos atores tomarem um caminho alternativo devido ao alto custo que isso implica. O resultado disso é o reforço do atrelamento entre as disputas eleitorais no nível nacional e nos níveis estaduais, permitindo a reiteração do fenômeno da nacionalização da competição eleitoral no país.

PALAVRAS-ChaVe Nacionalização da competição eleitoral; Democracia brasileira; Neo-institucionalismo.

ABSTRACT This article aims to analyze from the theoretical apparatus of new institutionalism the process of nationalization of electoral competition in Brazil, which has led to the approach in the way the Workers' Party (PT) and the Brazilian Social Democratic Party (PSDB) are articulated at the national and state levels. PT and PSDB have served as key political actors in the process of coalition formation in the Brazilian states, especially since the election of 1994, when both began to concentrate most of the votes in the race for the presidency, also gaining more political space at

Gostaria de agradecer os valiosos comentários e sugestões dos pareceristas anônimos da revista Teoria \& Pesquisa: Revista de Ciência Política. As imperfeições ainda presentes no artigo são de minha responsabilidade. 
the state level. Analyzing the trajectory of this process of linkage between the state and national dynamics, it is observed that this has been affected by positive feedback mechanisms, generating increasing returns which reiterate and reinforce the existence of the phenomenon. These mechanisms generate a path dependency that hinders the actors take an alternate route due to high costs that entails. The result is the strengthening of the linkage between the electoral disputes at the national and state levels, allowing the repetition of the phenomenon of nationalization of electoral competition in the country.

KEYWORDS Nationalization of electoral competition; Brazilian democracy; New institutionalism.

\section{Introdução}

O neoinstitucionalismo pressupõe que a política é estruturada pelas instituições, ou seja, que estas orientam e dão forma ao comportamento dos atores políticos. No entanto, dentro dessa abordagem, existem diferenciações internas que compreendem as instituições de diferentes formas, considerando sua relação com o contex to histórico, com o ambiente cultural e com os indivíduos. Ela é comumente dividida em três grandes correntes: institucionalismo da escolha racional, institucionalismo sociológico e institucionalismo histórico ${ }^{1}$.

A abordagem da escolha racional se fundamenta na concepção de que o comportamento de um ator é baseado no cálculo estratégico influenciado substantivamente pelas expectativas acerca do comportamento dos outros atores que participam do "jogo", tendo em vista a maximização do ganho individual. Já o institucionalismo sociológico considera que as formas e os procedimentos institucionais são considerados como práticas culturais, isto é, leva em conta não só o aspecto formal das instituições como orientadores da ação individual, mas também os padrões de significação originados dos sistemas de símbolos, dos esquemas cognitivos e dos modelos morais estabelecidos socialmente. Já o institucionalismo histórico, de modo geral, tem como perspectiva situar as instituições num espaço onde o contexto histórico estrutura decisões ulteriores,

\footnotetext{
${ }^{1}$ Outros teóricos têm separado as correntes do neoinstitucionalismo de diferentes formas. Kato (1996) explicita a existência de três, sendo elas: o institucionalismo sócio-histórico, o institucionalismo da escolha racional e uma síntese das duas primeiras, na qual a ação dos atores políticos estaria baseada numa racionalidade delimitada (bounded rationality). Já Nørgaard (2001) encontra seis vertentes: o institucionalismo normativo, o institucionalismo da escolha racional, o institucionalismo histórico, o institucionalismo empírico, o institucionalismo sociológico e o institucionalismo internacional.
}

estabelecendo regras formais e informais que orientam o comportamento dos indivíduos (Hall e Taylor, 2003; Steinmo, 2008).

Com o institucionalismo histórico, tem sido possível compreender as configurações organizacionais diante dos processos de longo alcance, de forma a perceber os mecanismos causais que irão dar origem às conjunturas críticas de um dado evento. A análise histórica das instituições aparece não como mera ilustração, mas como ferramenta necessária para a compreensão da relação de causalidade existente entre os eventos. É nesse sentido que o institucionalismo histórico contribui na elucidação de processos que dão forma ao comportamento político.

Essa corrente do neoinstitucionalismo tem sido utilizada tanto para a análise de mudanças quanto da inércia política. Ela aborda questões amplas, tendo como fonte de análise o tempo e as sequências históricas que explicam a continuidade ou alteração num dado fenômeno político. As instituições, assim, devem ser compreendidas como imersas dentro do contexto histórico, tentando observar os efeitos combinados entre instituições e as trajetórias históricas.

O foco da análise está nos eventos políticos situados historicamente, tentando responder por que um evento emergiu num dado contexto, observando também os casos em que o mesmo não surgiu, de modo a verificar quais condições históricas levam a sua manifestação. Assim, busca-se explicar as variações nos padrões ou eventos, tomando o comportamento dos atores políticos num dado contexto histórico. Nesse sentido, os pressupostos teórico-metodológicos do institucionalismo histórico podem colaborar com a compreensão da presidencialização ou nacionalização da competição eleitoral no novo contexto democrático 
brasileiro, devido à necessidade de retomar aspectos históricos e institucionais para a compreensão do mesmo.

A nacionalização da competição eleitoral é um fenômeno político em que as disputas eleitorais no nível nacional passam a influenciar as dinâmicas das eleições nos estados. No caso brasileiro, ela emerge num contexto institucional que a princípio favorece o surgimento de dinâmicas políticas particulares e diferenciadas entre si, devido à presença de um arranjo federativo, que permite a existência de esferas autônomas de poder nos estados e, por consequência, leva ao surgimento de interesses erguidos de acordo com as circunstâncias políticas regionais ${ }^{2}$. Contudo, percebe-se que tem havido uma tendência ao atrelamento entre as disputas eleitorais no nível nacional e estadual, principalmente a partir das eleições gerais de 1994, que deu origem ao processo denominado "presidencialização" ou "nacionalização da competição eleitoral", na qual a dinâmica de competição eleitoral estabelecida nas eleições presidenciais tem influenciado os pleitos nos estados brasileiros, o que tem impactado crescentemente na estratégia dos atores políticos estaduais quanto ao estabelecimento de coligações eleitorais (Braga, 2006; Cortez, 2009; Limongi e Cortez, 2010; Melo, 2007; Meneguello, 2010).

Tomando os questionamentos do institucionalismo histórico como norteadores para compreensão dos mecanismos causais da nacionalização da competição eleitoral no Brasil pergunta-se: como e por que tem ocorrido o gradual atrelamento entre as disputas eleitorais no nível nacional e no nível estadual a partir de $1994 ?^{3}$

Tendo em vista compreender melhor esse processo, este artigo foi estruturado em duas partes. $\mathrm{Na}$

\footnotetext{
$\mathrm{O}$ arranjo federativo permitiu o surgimento de interesses erguidos de acordo com as circunstâncias políticas regionais, que possibilitou o surgimento de "racionalidades políticas contextuais", próprias de cada unidade territorial (Lima Júnior, 1983, 1997). Lima Júnior considera que o comportamento partidário é condicionado pelo tempo e espaço político, ou seja, as condições de disputa levam ao surgimento de variabilidade das preferências eleitorais, considerando o nível de competição e o tamanho relativo do partido. Essas diferenças existem mesmo que o objetivo dos partidos seja a maximização do apoio eleitoral, pois o contexto modifica a forma como as organizações partidárias irão atuar (Lima Júnior, 1983: 33).

${ }^{3}$ É importante mencionar que nem todos os estados reproduzem as coligações estabelecidas no nível nacional, devido à dinâmica das correlações de força política estabelecidas historicamente nos estados, como os casos do Rio Grande do Sul e de Mato Grosso do Sul, onde PMDB e PT, por exemplo, não se aliam nas disputas para o Governo do Estado. Outro caso a ser destacado é do Maranhão, onde PT e DEM estiveram presentes na mesma coligação nas eleições de 2010 para o Governo do Estado. Diante dos limites analíticos deste artigo, não se focou nas particularidades regionais que impactam na ação estratégica de PT e PSDB no lançamento de candidaturas e na montagem de coligações.
}

primeira, parte-se da apresentação de categorias analíticas do neoinstitucionalismo, principalmente do institucionalismo histórico, como necessárias para análise de processos de longa duração histórica, como o caso da nacionalização da competição eleitoral no Brasil, realçando as concepções de conjuntura crítica, path dependence e retornos crescentes. $\mathrm{Na}$ segunda, constrói-se a explicação do surgimento e permanência da nacionalização da competição eleitoral no Brasil como resultado de processos de autorreforço que tornam possível a reiteração do fenômeno ao longo do tempo através de mecanismos de feedback positivo que levam os atores políticos estaduais a se orientarem, cada vez mais, pela lógica de disputas nacionais.

\section{Mudanças Institucionais e Path Dependence: A História Como Ferramenta de Análise}

Um dos principais objetivos da pesquisa empírica na área de Ciência Política é compreender a existência de um dado fenômeno político e não apenas descrevê-lo. Essa busca deve levar o pesquisador a tentar descobrir as variáveis que desencadeiam um dado evento. Para isso, deve-se considerar o contexto histórico no qual está imerso como modo de compreender as razões para o surgimento de tal fenômeno.

A causa opera em combinação com outras causas para produzir um resultado. Como afirma Mahoney (2008: 417-418), o conjunto dessas motivações gera o resultado, ou seja, duas ou mais variáveis são conjuntamente suficientes e/ou necessárias para um resultado. É o conjunto dessas variáveis necessárias que será suficiente para a explicação de um fenômeno. Para isso, portanto, deve-se ter em mente as razões para a existência do que se procura explicar, pensando não apenas em uma possível causa, mas num conjunto de elos causais que provocam o evento, o que pode levar à maior suficiência na explicação.

Diante disso, Daniel Little (1991) afirma que é possível descobrir as circunstâncias na história do evento que sejam relevantes para a sua ocorrência, afastando aquelas que se mostrem irrelevantes para a análise em questão. Para se alcançar esse objetivo, faz-se necessário traçar a narrativa histórica, cujo propósito é estabelecer as séries de eventos que conduzem as causas aos efeitos. Nesse sentido, entende-se que estudos de cunho descritivo podem ajudar a melhor compreender as razões que levam ao desencadeamento de um dado fenômeno na Ciência Política. A contextualização histórica pode, assim, elucidar como a nacionalização da competição 
eleitoral tem impactado os estados brasileiros. Ao analisar fenômenos que passam a ter longa duração na história, o pesquisador deve buscar as causas que desencadearam o evento, verificando possíveis mecanismos que reforçam a continuidade do mesmo.

Nesse sentido, Pierson (2004: 6) afirma que os pesquisadores que analisam fenômenos, dentro de um contexto histórico, devem se concentrar em seus mecanismos causais. Assim, devem ser examinados os processos temporais de modo a identificar e explicar seus mecanismos. Muito mais do que afirmar que a "história importa", deve-se entender que o conhecimento da história pode elucidar o modo como os eventos se conectam e se relacionam. Dessa forma, a compreensão das causas de um fenômeno que possuem alguma temporalidade depende do entendimento de como seus mecanismos têm uma forte dimensão temporal. Explorar o caráter desses mecanismos e as características dos contextos sociais e políticos que os geram pode elucidar os reais impactos dos eventos históricos sobre o fenômeno em análise.

Assim, sabe-se que os fenômenos políticos têm motivações anteriores relacionadas às formas como os atores se articulam e tomam decisões ao longo do tempo. As escolhas tomadas são derivadas das circunstâncias históricas das instituições, levando a posicionamentos que dependem de decisões tomadas anteriormente. As instituições se relacionam com a história, condicionando a forma como serão dispostas as regras e os procedimentos. A história, assim, passa a ser de fundamental importância para compreensão dos fenômenos políticos, principalmente aqueles que se perpetuam ao longo do tempo.

As mudanças institucionais são capazes de provocar novos comportamentos nos indivíduos por produzirem novos parâmetros a serem seguidos. À medida que as alterações nas instituições se consolidam, os atores passam a aceitar as novas regras, adaptando-se e tomando posicionamentos de acordo com as novas circunstâncias impostas. Nesse sentido, as mudanças institucionais podem provocar o início de uma trajetória dependente de escolhas que levará os atores a se posicionarem de forma similar ao longo do tempo, minimizando os possíveis custos que envolvam uma mudança nas escolhas. Posicionamentos tomados em um momento podem ser reforçados por escolhas subsequentes, criando uma trajetória histórica dependente, ou uma "dependência de trajetória" (path dependence), categoria esta presente no arcabouço teórico do institucionalismo histórico.

Path dependence pode ser definida como o processo em que o mundo social e político segue uma trajetória particular, diante de amplo número plausível de alternativas (Bennett e Elman, 2006: 464). Essa categoria é utilizada para explicar padrões temporais específicos, com amplas consequências geradas por determinados eventos, produzindo cursos de ação que dificilmente serão retrocedidos e que demandam um custo muito alto de reversão (Pierson, 2004).

A concepção de path dependence está intimamente ligada à ideia de que a causalidade social e política dependem da trajetória percorrida, ou seja, que as dinâmicas desatadas por um evento ou processo em um ponto no tempo se reproduzem (Pierson e Skocpol, 2008: 13). O comportamento dos atores, assim, deriva de decisões tomadas anteriormente, segundo a lógica de cada contexto político. A vida política, nesse caso, depende de propriedades políticas herdadas do passado (Hall e Taylor, 2003: 200-201). Ao se trilhar uma trajetória, os atores tendem a replicar decisões já tomadas anteriormente, diminuindo os custos e os riscos de outra escolha. Os custos de mudança de uma alternativa para outra aumentam marcadamente ao longo do tempo. Assim, ao se focar na sequência história de um fenômeno, ganha-se na compreensão tanto de processos de inércia quanto de mudança política (Pierson, 2004: 19).

Considerando os casos de inércia, é válido afirmar que esses sofrem processos de autorreforço, ou seja, existem feedbacks positivos que estimulam sua continuidade. Assim, quando um evento particular ocorre dentro de uma sequência de eventos, gerando feedbacks positivos, a história passa a ser relembrada (Pierson, 2004: 45). Retomar a sequência de eventos que gera a dependência de trajetória é útil para que se especifiquem os mecanismos reforçadores de uma trilha ou trajetória particular, evitando a mera descrição da estabilidade (Thelen, 1999) ${ }^{4}$.

Esses mecanismos que reforçam a continuidade histórica de um dado arranjo institucional, produzindo feedbacks positivos, são conhecidos como "retornos crescentes" (incresing returns) (Pierson, 2000). Estes são fundamentais para o prosseguimento de uma dada trajetória, sendo útil para análise de processos com longa duração histórica, de modo a verificar em que momento os atores políticos decidiram por escolhas que ratificassem o caminho já percorrido. Assim, o argumento do "retorno crescente" favorece a construção de hipóteses baseadas em uma ordenação temporal, considerando a sequência particular de eventos ou processos como parte fundamental para

\footnotetext{
${ }^{4}$ Sabe-se que nem todos os processos sofrem processos de feedback positivo, podendo haver incentivos para que atores políticos optem por outras alternativas. Entretanto, priorizei enfocar a discussão acerca dos processos políticos que sofrem autorreforço, em específico o caso da nacionalização da competição eleitoral no Brasil, o qual será analisado na última parte deste artigo.
} 
a explicação dos processos políticos com alguma temporalidade (Pierson, 2000: 252).

Segundo Pierson (2004: 79), muitos processos sociais importantes levam muito tempo para serem revelados, denominados como processos de longa duração (long-term process). Sobre esses processos, o autor enfatiza a existência de eventos em que as causas são cumulativas ou incrementais (slow-moving causal processes) e eventos cujos resultados ocorrem ao longo do tempo e cujas mudanças ocorrem de forma lenta e gradual (slow-moving outcomes).

Tanto causas quanto efeitos podem ser de longa duração. Assim como as causas de um evento podem ser ocasionadas pela inter-relação de acontecimentos que acumulam historicamente, as consequências podem emergir lentamente ao longo do processo de desenvolvimento do fenômeno político. Assim, os slow-moving outcomes são aqueles em que a mudança significativa na variável dependente ocorre apenas ao longo da trajetória histórica do processo (Pierson, 2004: 90). Os efeitos, portanto, irão se acumulando, avigorando um dado fenômeno.

$\mathrm{O}$ evento pode ser observado a partir do momento em que os efeitos começam a emergir. O momento que demarca o surgimento e o desencadeamento da trajetória histórica de um processo político ou social é denominado de momento ou conjuntura crítica (critical juctures), que é o marco do desenvolvimento da trajetória do processo ou evento (Pierson, 2000: 263). As conjunturas críticas são momentos em que mudanças institucionais importantes são produzidas, criando "bifurcações" que conduzem o desenvolvimento por um novo trajeto. Isso é resultado da ação de várias variáveis, não apenas de alterações institucionais. Instituições e agentes interagem gerando o momento crítico, o que indica a interdependência e interação entre as múltiplas variáveis causais de um evento (Steinmo, 2008).

A grande problemática consiste na explicação do que provoca os momentos críticos. O fato é que as razões para emergência da nova trajetória devem ser buscadas no contexto histórico, verificando-se quais processos deram origem ao fenômeno em análise. A especificação dos mecanismos causais específicos que provocam a path dependence, ou seja, a reprodução de uma instituição, é a chave para a teorização e melhor compreensão do desenvolvimento dos processos de estabilidade ou de mudança social e política (Pierson, 2004; Thelen, 1999).

Assim sendo, é necessária a análise tanto da conjuntura crítica (como o momento que demarca o início de uma trajetória), quanto dos retornos crescentes (que poderão reafirmar a trajetória, em caso de estabilidade institucional). No caso de alterações na rota de desenvolvimento de uma instituição, é imprescindível a explicação do mecanismo que ocasionou a mudança, visando à compreensão de quais momentos demarcaram a alteração na trajetória institucional.

Os acontecimentos históricos, assim, importam significativamente na análise política. Segundo Steinmo (2008), há pelo menos três razões pelas quais define a história como importante neste tipo de análise: 1) os acontecimentos políticos acontecem dentro de um contexto histórico, que tem consequência direta nas decisões e eventos; 2) os atores ou agentes podem aprender com a experiência, dependendo dos contextos sociais, políticos, econômicos e culturais particulares; e 3) as expectativas também são moldadas pelo passado. Assim, nota-se que a história não é uma cadeia de eventos independentes, pois se relacionam influindo nas decisões dos atores políticos.

Steinmo destaca ainda que os teóricos do institucionalismo histórico têm tido o esforço de compreender melhor os mecanismos causais das mudanças institucionais, verificando como as ideias (além de valores e crenças) desempenham papel fundamental na política e na história. A mudança institucional é produto de mudanças nas ideias dos atores. Ideias são entendidas como soluções criativas de problemas de ação coletiva, ou seja, quando se propõe uma alteração institucional para resolver um dado problema. Os encarregados de realizar tal mudança são motivados pela vontade de mudar as instituições em favor de novas ideias. Portanto, os atores capazes de tais reformas devem ser motivados por problemas e, logo, propõem mudanças institucionais. Os agentes, nesse sentido, entram na análise institucionalista como peças fundamentais nas mudanças históricas e institucionais.

Sobre o papel das ideias na mudança das instituições, Steinmo cita como exemplo a implementação das políticas neoliberais que se tornaram cada vez mais persuasivas, porque um número crescente de pessoas (as elites e os cidadãos comuns) foi persuadido pela lógica do argumento neoliberal. As políticas de enxugamento da máquina pública, que incluíam cortes de impostos e regulações pró-mercado, eram ideias que tinham como proposta limitar as tendências inflacionárias, possibilitando mais recursos econômicos para a iniciativa privada, a qual poderia reinvestir e restringir os gastos e os desperdícios do governo.

As reformas, nessa ótica, são resultado de novas concepções de como devem ser formatadas as instituições, emergindo regras e procedimentos que passam a nortear o comportamento dos indivíduos. Depois de implementadas as reformas, as instituições 
podem contribuir para manter determinadas práticas devido aos retornos crescentes, que geram dinâmicas de autorreforço, dificultando mudanças ao longo da trajetória histórica tomada pelas instituições. Estas se consolidam à medida que percorrem uma maior trajetória, o que eleva os custos dos atores escolherem outra alternativa que foi abandonada anteriormente. Os arranjos institucionais colocados passam a ser barreiras que impedem uma reversão fácil da escolha inicial (Fernandes, 2002; Pierson, 2000, 2004). Assim, a trajetória tomada pelas instituições passa a ser reiterada pelos mecanismos de autorreforço, que irão gerar feedbacks positivos, possibilitando a manutenção do arranjo institucional observado.

As instituições formatadas afetam diretamente os indivíduos e as decisões coletivas. As reformas, assim, geram mudanças no cálculo dos atores, que passam a se articular estrategicamente de acordo com as novas regras impostas (Nascimento, 2009). Esses atores agem seguindo as regras da configuração institucional imposta, tentando obter, através de cálculos específicos, o melhor retorno possível. Por um lado, a trajetória histórica das instituições influencia na forma como os atores respondem a essas mudanças, por outro, esses terão fundamental papel na condução das instituições, seja mantendo ou alterando sua configuração inicialmente estabelecida.

O institucionalismo histórico leva em conta a relação existente entre instituições e indivíduos, compreendendo os comportamentos dos atores políticos em referência às instituições dadas historicamente (Nørgaard, 2001: 27). Porém, o institucionalismo da escolha racional tem uma importante contribuição com as análises que partem do institucionalismo histórico para entender a relação instituição-indivíduo, que é "modelar os mecanismos através dos quais os atores fazem escolhas durante períodos históricos chave" (Mahoney, 2005: 330, tradução minha). $\mathrm{O}$ institucionalismo da escolha racional, nesse sentido, pode fornecer elementos para compreender o cálculo dos atores políticos na realização de uma escolha, considerando os incentivos institucionais.

Assim sendo, entende-se que as análises que partem do pressuposto do institucionalismo histórico podem também receber contribuições do institucionalismo da escolha racional, devido ao papel que as escolhas dos atores podem desempenhar na continuidade de determinados arranjos. Mesmo sob constrangimentos institucionais, em momentos de escolha, os atores adotam posições baseando-se em cálculos estratégicos que resultem em um melhor resultado para eles. Sabe-se que escolhas diferentes poderiam levar a trajetórias diferentes. Portanto, as escolhas estratégicas dos indivíduos devem ser levadas em conta para a compreensão dos processos de mudança institucional que acarretem no desencadeamento de determinados processos políticos de longa duração.

Diante disso, a partir da discussão empreendida sobre as categorias do neoinstitucionalismo, na próxima seção será analisado o processo de nacionalização da competição eleitoral, levando em conta o seu surgimento, a conjuntura crítica (que demarca a origem do processo político), os processos de autorreforço (que geram a trajetória dependente) e a ação dos atores políticos diante das reformas institucionais implementadas durante o novo contexto democrático brasileiro.

\section{Processo de Nacionalização da Competição Eleitoral no Brasil: Compreendendo sua Trajetória}

Processos de transição à democracia, em geral, produzem grandes transformações nas instituições políticas devido ao surgimento de novas "ideias" ou concepções de como essas devem ser. No Brasil, esse processo ocorreu junto com reformas institucionais que buscavam garantir aos cidadãos maior participação política e representatividade no âmbito da política estatal. As alterações propostas tinham explícita a necessidade de maior democratização da esfera pública, contrapondo-se ao autoritarismo do regime militar. Com isso, havia a necessidade de se aprovar uma legislação que estimulasse a criação de novos partidos políticos que pudessem tornar a representação mais plural.

Juntamente com a realização de eleições livres em todos os níveis federativos, o multipartidarismo foi um marco para a construção do regime democrático no país. As duas principais reformas institucionais que possibilitaram a reorganização dos partidos políticos na transição à democracia foram: 1) a Lei n ${ }^{\circ} 6.767$, de 20 de dezembro de 1979, que possibilitou o retorno ao multipartidarismo; e 2) a Emenda Constitucional $\mathrm{n}^{\circ}$ 25 , de 15 de maio de 1985, que flexibilizou a criação de novos partidos políticos, garantindo também a reorganização das agremiações partidárias que tinham sido impossibilitadas de obter registro durante a vigência do regime militar (Schmitt, 2000).

Essas mudanças possibilitaram maior acirramento da competição eleitoral, permitindo o surgimento e a consolidação de múltiplos partidos. Além disso, o retorno à democracia trouxe a possibilidade de se constituir coligações eleitorais (através da Lei $\mathrm{n}^{\circ}$ 7.454, de 30 de dezembro de 1985), o que ampliou as 
possíveis formas de articulação entre as agremiações partidárias no novo contexto democrático ${ }^{5}$.

A instituição do arranjo multipartidário juntamente com a possibilidade de formar coligações eleitorais foram reformas que deram vazão à necessidade de pluralizar a representação política no país. A tendência foi a ampliação das possibilidades de escolha pelo eleitorado, pois um número significativo de agremiações partidárias foram criadas e passaram a se agregar em forma de coligações. Em geral, os partidos passaram a se utilizar das coligações como forma de ampliar sua capacidade de eleger representantes para o Legislativo. Os partidos menores buscaram ocupar algum espaço na política com a ajuda da força eleitoral de partidos maiores, que, por sua vez, utilizaram as coligações como forma de ampliar, ainda mais, sua força na arena eleitoral.

Essas reformas possibilitaram a elevação da fragmentação partidária no âmbito do Legislativo, resultado do crescimento e do desenvolvimento das agremiações. Com isso, o número de partidos apresentado ao eleitorado cresceu substantivamente ao longo dos anos, o que representa um alto custo para a realização da escolha. As coligações visam, assim, minimizar esse custo, principalmente nas eleições para o Executivo, provocando a diminuição do número de opções oferecidas aos votantes.

Nesse sentido, as alterações institucionais favoreceram a passagem de um sistema bipartidário, imposto pelo regime militar, para um multipartidário emergido no processo de redemocratização. A flexibilidade garantida pela legislação para a organização de partidos e a necessidade de se estabelecer partidos competitivos com projetos políticos nacionais possibilitou a emergência de dois partidos que têm conduzido as disputas eleitorais presidenciais desde 1994: o Partido dos Trabalhadores (PT) e o Partido da Social Democracia Brasileira (PSDB).

O PT foi criado em 1980 e tem formação oriunda do movimento sindical e de segmentos populares apoiados por uma parcela da Igreja Católica, sendo um caso raro de partido criado de baixo para cima (Meneguello, 1989; Schmitt, 2000). Desde sua criação, o partido apresentou forte vinculação com os movimentos sociais e com a necessidade de ampliar os direitos sociais, com ênfase nas garantias

\footnotetext{
5 Já havia a possibilidade de ser estabelecer associações partidárias no Código Eleitoral de 1950, sob o nome de alianças. Durante o período militar, com o Código Eleitoral de 1965, houve a proibição das alianças eleitorais. Somente em 1985, ocorreu o restabelecimento da possibilidade de montagem de associações partidárias para as eleições proporcionais, sob o nome de coligações (Krause e Schmitt, 2005: 11-12).
}

aos trabalhadores, marcando posição na esquerda do espectro ideológico. Elegeu dois presidentes para três mandatos: Luís Inácio Lula da Silva, eleito em 2002 e reeleito em 2006, e Dilma Rousseff, eleita em 2010.

Já o PSDB surgiu em 1988 como uma dissidência de uma ala de parlamentares do PMDB que se autodenominava como a mais progressista do partido, diferenciando-se do governo do peemedebista José Sarney e de sua base de sustentação baseada no PMDB e no PFL (Roma, 2002). Com a vitória de Fernando Henrique Cardoso na disputa para a Presidência da República de 1994, houve a construção de uma coalizão de centro-direita, tendo como principais partidos aliados PMDB, PFL e PTB. O peessedebista foi reeleito em 1998, após promulgação da Emenda Constitucional $\mathrm{n}^{\circ} 16$, em 4 de junho de 1997, que garantiu ao Presidente da República, Governadores de Estado e do Distrito Federal e aos Prefeitos a possibilidade de pleitear a recondução ao cargo para um único período subsequente. Segundo Roma (2002), o governo peessedebista implantou um programa de reformas liberalizantes, como os processos de "desregulamentação da economia, abertura econômica ao capital estrangeiro e privatização das empresas estatais" (Roma, 2002: 75).

Nota-se, assim, que apesar das diferenciações entre PSDB e PT, ambos os partidos têm tido uma "vocação presidencialista" mais consistente (Melo e Câmara, 2012: 81-82). Os dois partidos têm se articulado nacionalmente buscando construir candidaturas presidenciais competitivas. Nesse sentido, essas agremiações têm se apresentado ao eleitorado brasileiro como as principais alternativas para as grandes questões nacionais. Sobre este ponto, afirma Echegaray:

Avaliados em sua competência para resolver diferentes assuntos - da violência à corrupção, do desemprego à educação, do crescimento econômico ao meio ambiente -, somente os dois grandes agrupamentos partidários do PT e do PSDB são reconhecidos como capazes por uma maioria expressiva. O resto da oferta eleitoralpartidária simplesmente carece de força suficiente em qualquer uma dessas áreas específicas para disputar um espaço com o atual bipartidarismo [...] (Echegaray, 2007: 16).

A condução das eleições nacionais por PT e PSDB começou a partir de 1994. Antes disso, houve apenas uma eleição direta para a presidência, em 1989. Neste pleito, ambos partidos saíram derrotados para o candidato do PRN, Fernando Collor. No primeiro turno, as candidaturas do PT e do PSDB obtiveram apenas $28,7 \%$ dos votos válidos, num total de 21 pleiteantes. A mudança ocorreu em 1994, quando ocorreram as primeiras "eleições casadas" no novo 
contexto democrático, onde seriam escolhidos o Presidente da República, Governadores, Deputados federais e estaduais, além de $2 / 3$ dos senadores do Congresso. Nessas eleições, Fernando Henrique Cardoso, do PSDB, foi eleito num pleito que contava com oito candidatos no total (número substancialmente menor do que da "eleição solteira" de 1989). Na eleição de 1994, as candidaturas de PSDB e PT obtiveram 81,3\% dos votos válidos, uma proporção quase três vezes maior do que o percentual de votos obtidos pelos dois partidos no pleito anterior.

A eleição de 1994 é considerada como conjuntura crítica do surgimento da presidencialização ou nacionalização da competição eleitoral, dando origem ao desenvolvimento do processo de coordenação estratégica de candidaturas pelo PT e PSDB nos níveis nacional e estadual. Dentre os fatores institucionais, destacam-se as mudanças ocorridas durante o processo de retorno à democracia, como o advento do multipartidarismo, a flexibilização da criação de partidos políticos num ambiente de eleições livres e diretas e a possibilidade de se formar coligações eleitorais. Além disso, em 1994, houve a realização de "eleições casadas", condição institucional que garantiu ao PSDB e ao PT a construção de candidaturas competitivas, lançando mão de estratégias nacionais para as candidaturas ${ }^{6}$. Assim, a concomitância das eleições nacionais e estaduais permitiu o lançamento de duas candidaturas competitivas no nível nacional possibilitando a agregação de forças em torno dos dois pólos nos estados. A partir de 1994, as candidaturas nos estados começaram a ser crescentemente orientadas pela lógica de disputas eleitorais para a presidência.

A partir desse marco, a clivagem PT-PSDB tem ganhado estabilidade no plano nacional, gerando efeitos sobre a ação dos atores políticos nos estados, que paulatinamente tem passado a se orientar pelo modo como esses partidos se articulam estrategicamente no nível nacional (Cortez, 2009). De acordo com Cortez (2009), trata-se do mecanismo de construção nacional das candidaturas pelos dois partidos, orientando as estratégias de montagem de coligações eleitorais. Segundo o autor:

[...] a estratégia assumida por PT e PSDB foi reproduzir nos Estados a clivagem política do pleito presidencial. Trata-se da federalização das competições para governador [...] (Cortez, 2009: 141).

\footnotetext{
6 "No caso brasileiro, no que tange à vinculação entre os planos nacional e estadual, houve em primeiro lugar duas eleições não concomitantes, em 1982 e em 1986, em que estavam em disputa apenas cargos cujos 'distritos' eram estaduais (governadores, senadores e deputados estaduais e federais), e somente depois uma eleição nacional presidencial mas 'solteira', em 1989 [...]" (Abrucio e Samuels, 1997: 154).
}

Isso reforça a argumentação de Melo (2010: 8) ao afirmar que as candidaturas no Brasil têm sido montadas com "[...] a primazia da estratégia presidencial sobre a dinâmica local [...]".

A força de PT e PSDB nas eleições presidenciais decorre, em grande parte, da capacidade que esses partidos têm de coordenar a composição de coligações eleitorais. As estratégias nacionais traçadas por esses partidos incluem os estados, havendo, portanto, o condicionamento das estratégias dos atores políticos estaduais (Cortez, 2009, 2010). As lideranças das agremiações, assim, têm consciência de que as eleições nacionais dependem das estratégias traçadas nos estados, já que é nesse âmbito que os partidos podem mobilizar os eleitores e expor seu programa político localmente (Van Houten, 2009). Partidos como PT e PSDB, que têm buscado a vitória nas eleições presidenciais, dependem das estratégias traçadas nos estados, o que implica no trabalho de coordenação estratégica na montagem de alianças e coligações eleitorais.

De 1994 a 2010, as disputas eleitorais para a presidência foram centradas entre PT e PSDB. Dos cinco pleitos realizados $(1994,1998,2002,2006$, e 2010), os partidos obtiveram, em todos os casos, mais de $80 \%$ dos votos válidos no primeiro turno. Além disso, dessas disputas, o PT saiu vitorioso três vezes e o PSDB duas. As estratégias de coligação eleitoral dos partidos têm os colocado de lados opostos nos estados, criando uma dinâmica onde as forças políticas tendem a se orientar pela lógica de disputas para o Executivo nacional, visando a um maior retorno eleitoral para a agremiação partidária. De acordo com Limongi e Cortez:

PT e PSDB são os principais protagonistas das eleições presidenciais. Asseguraram esta posição em 1994 e não a perderam nas eleições subsequentes. Processos eleitorais são dotados de grande força inercial. $\mathrm{O}$ alto custo de entrada nas eleições presidenciais desestimula a participação de potenciais desafiantes. Para estes, negociar a troca de apoios pode ser mais vantajoso. Partidos coordenam suas estratégias nos diferentes planos, articulando o lançamento (e a retirada) de candidaturas nos diferentes distritos. [...] A polarização da disputa presidencial foi transplantada aos estados. PT e PSDB também são os mais fortes contendores nas eleições para governador. Recebem mais votos e controlam mais governos do que os demais. Quando não estão presentes, são representados por seus aliados históricos, PSB e DEM respectivamente, ou por uma aliança circunstancial com o PMDB [...] (Limongi e Cortez, 2010: 36).

Os dados mostram que PT e PSDB, em geral, colocam-se de lados opostos nas disputas eleitorais 
nos estados. Considerando a eleição de 1990 como a primeira em que PSDB concorreu a cargos eletivos, verifica-se, na Tabela 1, que as diferenças entre os partidos já estavam postas, o que impedia, na maior parte dos casos, a formação de coligações entre os dois partidos nos estados. De 1990 a 2010, ocorreram seis pleitos para governador nos 27 estados brasileiros, ou seja, foram 162 disputas eleitorais. Desse total, houve 134 coligações que contavam com PT e PSDB de lados opostos, ou seja, em 82,7\% dos casos. Em apenas sete casos, PT e PSDB participaram da mesma coligação: em 1990, no Amazonas, Amapá e Pará; em 1994, no Mato Grosso e em Santa Catarina; e, em 1998, no Acre e no Piauí.

Porém, as coligações das quais participavam PT e PSDB dificilmente conseguiam fazer frente às forças políticas estaduais hegemônicas e tradicionais. O desempenho pouco expressivo de ambos os partidos nas disputas para os governos estaduais era um indício da ausência de uma estratégia nacional que alavancasse as candidaturas para os Executivos estaduais. É a partir das eleições de 1994 que PT e PSDB passaram a conduzir as disputas eleitorais para a Presidência da República, gerando impactos nas dinâmicas eleitorais nos estados, principalmente quanto à ampliação da força eleitoral de PSDB e PT (ver Tabela 1).

Desde 1994 que se observa o crescimento da força eleitoral dos partidos nos cenários estaduais. PT e PSDB elegeram apenas um governador em 1990. Em 1994, ambos partidos conquistaram oito governos estaduais, sendo seis governadores do PSDB e dois do PT. Em 1998 e 2002, o número de governadores eleitos pelos partidos foi de 10, passando para $11 \mathrm{em}$ 2006, e 13 em 2010. Assim, desde 1994, o PSDB e o PT têm elegido parcela significativa dos governadores brasileiros.

Ademais, PT e PSDB têm ampliado substancialmente o número de coligações vitoriosas.
Enquanto em 1990, apenas o PSDB participou de coligações vitoriosas (seis, no total), em 1994, o mesmo partido participou de 12 e o PT de quatro, somando um total de 16. Esse número se manteve nas eleições de 1998 e 2002, ampliou para 17 em 2006, e aumentou para 24 em 2010. Ambos os partidos têm participado da maior parte das coligações vencedoras, desde 1994, sendo que, em 2010, 92,6\% das coligações vencedoras nos pleitos para governador tiveram a participação de um dos dois partidos, evidenciando, ainda mais, o atrelamento entre as dinâmicas nacional e estadual, fruto das estratégias traçadas nacionalmente por PT e PSDB.

Nesse sentido, pode-se afirmar que no novo contexto democrático existem dois períodos: um, anterior às eleições de 1994, no qual as dinâmicas políticas estaduais teriam uma lógica própria a ponto de ter uma forma de racionalidade própria, diferenciada da dinâmica política nacional (Lima Júnior, 1983, 1997); e de 1994 a 2010, cuja influência das disputas presidenciais nas dinâmicas políticas estaduais mostra que a trajetória democrática no Brasil tem levado ao imbricamento entre as dinâmicas políticas estaduais e a nacional. A lógica de disputas eleitorais assumidas nesse período tem influenciado na montagem das coligações, indicando a presença de fatores da política nacional como intervenientes na política estadual.

A partir de 1994, portanto, há uma mudança na lógica de formação de coligações, pois, antes disso, os arranjos políticos estaduais possuíam uma lógica própria, diferenciada da dinâmica política nacional (Braga, 2006; Cortez, 2009; Limongi e Cortez, 2010; Melo, 2007; Meneguello, 2010). Com a mudança na forma de coordenar estrategicamente as candidaturas, o sistema partidário passou a adquirir cada vez mais clareza para os atores políticos estaduais, que passam a procurar o estabelecimento de estratégias de forma conjunta, desde o momento da composição de alianças

Tabela 1. Disputa entre PT e PSDB nas eleições para os governos estaduais brasileiros (1990-2010).

\begin{tabular}{lccccccc}
\hline & $\mathbf{1 9 9 0}$ & $\mathbf{1 9 9 4}$ & $\mathbf{1 9 9 8}$ & $\mathbf{2 0 0 2}$ & $\mathbf{2 0 0 6}$ & $\mathbf{2 0 1 0}$ & Total \\
\hline Coligações PT vs. PSDB & 22 & 19 & 23 & 21 & 22 & 27 & 134 \\
$\begin{array}{l}\text { Vitória de coligações com } \\
\text { participação do PSDB }\end{array}$ & 6 & 12 & 11 & 12 & 10 & 12 & 63 \\
$\begin{array}{l}\text { Vitória de coligações com } \\
\text { participação do PT }\end{array}$ & 0 & 4 & 5 & 4 & 7 & 13 & 33 \\
$\begin{array}{l}\text { Governadores eleitos do PSDB } \\
\text { Governadores eleitos do PT }\end{array}$ & 1 & 6 & 7 & 7 & 5 & 8 & 34 \\
\hline
\end{tabular}

Fonte: Tribunal Superior Eleitoral (TSE), Meneguello (2010) e Banco de Dados de Jairo Nicolau (Disponível em: http://jaironicolau. iesp.uerj.br). 
e coligações, que incidirá sobre as disputas eleitorais $\mathrm{e}$, consequentemente, nos governos formados.

Assim, desde 1994, há o desenvolvimento de uma path dependence, de forma que "decisões tomadas em um pleito podem influenciar as subsequentes" (Melo, 2010: 8). PSDB e PT passaram a ser os condutores das disputas eleitorais para a presidência, sendo que as coligações nacionais têm norteado o comportamento dos atores políticos nos estados. Ademais, duas alterações institucionais implementadas pós-1994 possibilitaram um ambiente institucional mais favorável à trajetória de nacionalização da competição eleitoral: 1) o estabelecimento da reeleição para os cargos majoritários, em 1997, no qual Presidente da República, Governadores de Estado e do Distrito Federal e os Prefeitos passaram a poder pleitear a recondução ao cargo para um único período subsequente; e 2) em 2002, foi instituída, pelo Tribunal Superior Eleitoral, a verticalização das coligações partidárias, impondo maior simetria entre as alianças partidárias para Presidente da República e as coligações proporcionais ${ }^{7}$.

Com a reeleição, aumentou-se a possibilidade de continuidade de um dado grupo político à frente do poder, o que estimulou, ainda mais, os atores políticos a se articularem em torno de candidaturas ou governistas ou oposicionistas, reforçando a bipolaridade das disputas eleitorais nacionais e estaduais. As coligações passaram a agregar um grande número de partidos e a quantidade de candidaturas para os cargos majoritários tendeu a diminuir em função da estratégia coligacionista, reforçada ainda mais com o advento da reeleição, que diminuiu as chances de pequenos partidos alçarem o poder.

Já a verticalização das coligações eleitorais, apesar de ter ocorrido apenas em 2002 e 2006, criou limites mais rígidos para a construção de alianças nas eleições presidenciais e estaduais. Assim, partidos que lançaram candidaturas para as eleições presidenciais não puderam se coligar nos estados, havendo, assim, a formalização da clivagem presidencial. Nesse sentido, Cortez afirma que:

\footnotetext{
A intenção era inibir a formação de "coligações esdrúxulas". Contudo, observou-se que, nas eleições de 2002 e 2006, houve o florescimento de alianças informais (Sousa, 2006; Fleischer, 2006, 2007). Isso pode ser explicado pelas diferenças e particularidades políticas regionais, historicamente construídas nos estados brasileiros, o que implica numa minimização do impacto da nacionalização da competição eleitoral. Determinados arranjos políticos estaduais se perduram no tempo, mas têm tendido a se modificar diante das estratégias eleitorais nacionalmente estabelecidas pelos partidos.
}

Essa capacidade de articular os pleitos, que nos anos anteriores foi oriunda das respostas dos partidos, a partir de 2002 passou a ser exigência da legislação eleitoral. Nota-se que, de fato, os partidos que disputaram a presidência passaram a ficar de forma mais efetiva em lados opostos nas disputas estaduais. A verticalização, de fato, reforçou a nacionalização do conflito presidencial nos Estados ao eliminar as estratégias que seriam contrárias ao padrão de conflito nacional [...] (Cortez, 2009: 90).

PT e PSDB se fortaleceram à medida que foram ganhando mais postos eleitorais. A estratégia dos partidos de coordenação eleitoral de ambos, num quadro institucional favorável, permitiu que essas organizações partidárias paulatinamente passassem a ser os dois pólos de referência da política nacional. A preponderância de ambos partidos nas disputas eleitorais para a presidência é resultado da articulação de PT e PSDB com as candidaturas nos estados, construindo palanques nos diferentes distritos, potencializando suas forças eleitorais. Os demais partidos tendem a se agrupar em torno de um dos dois pólos, através de coligações e alianças nos estados. Como afirma Cortez, "PT e PSDB reproduzem o conflito nacional nos diferentes distritos, ainda que nem sempre se façam presentes de forma direta nestas disputas [...]" (Cortez, 2009: 17). Esse processo se construiu a partir do surgimento de efeitos institucionais incrementais ou cumulativos, ao longo do tempo, permitindo que PT e PSDB se articulassem estrategicamente nas disputas à presidência e para os governos estaduais.

Assim, as estratégias eleitorais têm sido orientadas, cada vez mais, por PT e PSDB, que têm conduzido a formação de candidaturas nacionais e estaduais - ora governistas, ora oposicionistas. Com isso, as coligações nos estados têm sido conduzidas por dois processos relacionados entre si: 1) pela tradução do arranjo competitivo presidencial pelas coligações vencedoras nos estados (Meneguello, 2010: 15); e 2) a preponderância do Poder Executivo sobre a dinâmica das coligações estaduais, devido à concentração de poder nas mãos do governador, que pode garantir aos partidos aliados a oportunidade de acesso aos recursos da máquina pública (Krause, 2010: 14-15). A viabilidade de mudança eleitoral, nesse sentido, torna-se mais possível com a agregação das forças políticas oposicionistas em torno de amplas coligações, que, em geral, são pensadas nacionalmente.

Assim, os atores políticos estaduais têm sido, cada vez mais, constrangidos pelas decisões tomadas 
pela cúpula dos partidos, principalmente de PT e PSDB. Como afirmam Melo e Câmara (2012), o "mecanismo de reprodução", ou seja, a decisão dos partidos nos estados de se alinharem ao nível nacional, é encontrada na "ação dos petistas e tucanos", pois:

Dentre os maiores partidos brasileiros, PT e PSDB foram os únicos a se mostrarem capazes de (1) formular um projeto de política nacional, (2) apresentar candidatos competitivos às eleições presidenciais e (3) se unificar em torno de (1) e (2). PT e PSDB sempre tiveram claro que as decisões tomadas na arena principal - a presidencial - deveriam subordinar as demais. Mas, pelo menos até 2002, isso teve consequências distintas para os dois partidos. Mesmo antes da primeira eleição presidencial, a estratégia petista sempre foi claramente nacional - tratava-se de firmar um projeto político, de levar o partido ao maior número de estados possível, correndo em faixa própria com seus símbolos e seu discurso. [...] No caso do PSDB a candidatura presidencial sempre procurou apoio em candidatos estaduais competitivos, fossem eles do PSDB ou não. Em consequência, o número de candidaturas próprias aos governos estaduais, entre 1990 e 2010, foi bem menor que os lançados pelo PT [...] (Melo e Câmara, 2012: 83).

Sendo assim, a conjuntura crítica de 1994, com o início da bipolarização das disputas presidenciais entre PSDB e PT, e os incentivos institucionais que favoreceram o estreitamento das dinâmicas eleitorais nacionais e estaduais não geraram mecanicamente o processo de nacionalização da competição eleitoral. Isso se deveu à coordenação estratégica dos pleitos por PT e PSDB, que buscaram estabelecer palanques nos estados, e, consequentemente, passaram a montar coligações de lados opostos também nos estados. No nível estadual, os atores políticos tiveram suas estratégias coligacionistas influenciadas pela articulação estratégica dos partidos, principalmente das candidaturas presidenciais de PT e PSDB. Os incentivos institucionais e a ação estratégica desses dois partidos foram fundamentais para o condicionamento do comportamento das lideranças políticas estaduais e estas compreenderam a vinculação às candidaturas presidenciais como uma forma de aumentar o potencial eleitoral de suas candidaturas. Alinhando-se às candidaturas nacionais mais competitivas foi possível que houvesse a agregação de mais partidos em amplas coligações eleitorais. Assim, mesmo com a variedade de coligações existentes nos estados, é evidente que a clivagem das disputas presidenciais tem impactado nas dinâmicas eleitorais estaduais.

\section{Considerações Finais}

A busca pela compreensão do fenômeno da nacionalização da competição eleitoral no Brasil deve pressupor a análise de como os aspectos institucionais se conjugaram com a re-orientação dos atores políticos no novo contexto democrático. Situar essas mudanças historicamente, portanto, é fundamental para caracterizar a conjunção de causas que influenciam a trajetória de um fenômeno político, assim como a identificação da conjuntura crítica, a qual marca o início de seu trajeto de desenvolvimento.

Nesse sentido, observa-se que o padrão de competição política no nível nacional tem sido gradualmente transposto para as dinâmicas estaduais, devido a fatores institucionais presentes no novo contexto democrático brasileiro. Essa tendência começou a se desenvolver a partir da realização de eleições casadas, em 1994, marcando, assim, o momento crítico para o surgimento da trajetória da nacionalização da competição eleitoral. Observou-se, desde então, uma progressiva ampliação da interdependência entre as disputas eleitorais nos níveis nacional e estadual.

Sendo assim, retoma-se a pergunta posta no início deste artigo: por que houve o processo de atrelamento das disputas eleitorais à presidência e para os governos estaduais a partir de 1994? Os fatores institucionais foram fundamentais para o desenvolvendo do processo de nacionalização. Mudanças institucionais surgidas no novo contexto democrático, como a realização de eleições diretas e livres, o retorno ao multipartidarismo, a flexibilização para a criação de partidos, a possibilidade de se realizar coligações eleitorais possibilitou a criação de muitas organizações partidárias que passaram a disputar pleitos eleitorais. Com o advento das "eleições casadas" em 1994, PT e PSDB encontraram o momento propício para articular candidaturas nacionais com grande lastro eleitoral. Assim, passaram a coordenar nacionalmente as estratégias eleitorais visando à aproximação entre as alianças nacionais e estaduais. Partindo de um ambiente institucional favorável, as agremiações buscaram criar estratégias que possibilitassem maior retorno eleitoral. Assim sendo, PT e PSDB tenderam a reproduzir nos estados a clivagem das disputas presidenciais, seja diretamente, pelo lançamento de candidaturas próprias, ou indiretamente, pela participação dos partidos em coligações cujo candidato ao Governo do Estado é de outro partido aliado. Assim, através de uma ação estratégica, PT e PSDB têm participado de candidaturas competitivas tanto no nível nacional quanto nos estados.

PT e PSDB se tornaram os dois pólos norteadores do funcionamento do sistema político brasileiro. PT, 
situado à esquerda, tem agregado forças políticas como PCdoB, PSB e PDT, e o PSDB, situado à direita do PT, tem sido apoiado pelo DEM. Entre os dois pólos estão partidos que têm mudado de posição de acordo com a composição dos governos no nível nacional, como o PMDB, central para a manutenção da governabilidade tanto no nível nacional quanto nos estados. A consolidação dessa tendência tem levado a um processo de path dependence que leva os atores políticos estaduais a se orientarem, paulatinamente, pela lógica de disputas nacionais. Isso ocorre devido aos constrangimentos estabelecidos pelas estratégias nacionais dos partidos ou pelo incentivo de participar de amplas coligações, visando à obtenção de espaço político no governo eleito. As candidaturas presidenciais de PT e PSDB buscaram construir palanques eleitorais nos estados, ou lançando candidaturas ou apoiando outras candidaturas majoritárias. E os principais pleiteantes aos cargos de governador têm tendido a se vincular às candidaturas presidenciais petista e peessedebista.

Um aspecto que não foi explorado neste artigo, mas que deve ser analisado em trabalhos futuros, refere-se às particularidades regionais que podem operar como atenuantes ao processo de nacionalização da competição eleitoral promovido por PT e PSDB. Os arranjos políticos regionais construídos historicamente podem impedir que a clivagem PT-PSDB seja reproduzida em determinados contextos, ou mesmo que a agregação de forças se deem em torno dos dois pólos. Assim, partidos que se coligam nacionalmente podem não se aliar nos estados devido às disputas entre lideranças políticas regionais, que podem ter mais influência no estabelecimento de coligações nos estados do que as estratégias traçadas nacionalmente.

As coligações estaduais, portanto, nem sempre reproduzem o conflito político estabelecido entre os partidos nacionalmente. Apesar de ser impactada pelo processo de coordenação eleitoral de PT e PSDB, a formação de coligações nos estados depende também de fatores regionais, ou seja, das estratégias das lideranças políticas estaduais, das variáveis relativas ao processo de barganhas, das aproximações e dos distanciamentos dados historicamente entre os partidos nos estados. Isso se deve ao caráter não-linear que, por vezes, toma os fenômenos políticos, diante da presença de fatores históricos que limitam o impacto de determinados processos políticos. É nesse sentido que Brown e Bruce (2002: 636) afirmam que enquanto as forças políticas organizam a competição partidária - tanto no nível nacional e estadual - as configurações políticas dos estados, dadas historicamente, podem servir para aumentar ou diminuir seus efeitos.
Portanto, se, por um lado, a path dependence possibilita aos novos arranjos institucionais provocar efeitos incrementais e cumulativos que levam a progressiva ampliação da nacionalização da competição eleitoral, por outro lado, as forças políticas estaduais constituídas historicamente também podem atuar como atenuantes ao desenvolvimento desse processo. Porém, é patente que as configurações políticas nos estados têm passado a se orientar, cada vez mais, pelas estratégias estabelecidas nacionalmente pelos partidos.

Assim, sendo os partidos mais competitivos nas eleições presidenciais desde 1994, PT e PSDB têm organizado e influenciado a montagem das coligações estaduais. Isso foi motivado por incentivos institucionais cumulativos, que possibilitaram ao sistema político brasileiro maior clareza, inclusive quanto ao estabelecimento de estratégias eleitorais dos partidos. Esses passaram a se agregar em amplas coligações, diminuindo o número de opções eleitoralmente viáveis nas eleições majoritárias, reduzindo-as, na maioria dos casos, a uma dinâmica bipartidária, centrada em torno de PSDB e PT.

\section{Referências}

Abrucio, Fernando e Samuels, David. 1997. A nova política dos governadores. Lua Nova, 40-41: 137-166.

Bennett, Andrew e Elman, Colin. 2006. Qualitative research: recent developments in case study methods. Annual Review of Political Science, 9: 455-476. http:// dx.doi.org/10.1146/annurev.polisci.8.082103.104918

Braga, Maria do Socorro. 2006. O processo partidárioeleitoral brasileiro: padrões de competição política (1982-2002). São Paulo: Associação Editorial Humanitas/Fapesp.

Brown, Robert e Bruce, John. 2002. Political parties in state and nation: party advantage and party competition in a federal setting. Party Politics, 8(6): 635-656. http://dx.doi.org/10.1177/1354068802008006001

Cortez, Rafael. 2009. Eleições majoritárias e entrada estratégica no sistema partidário-eleitoral brasileiro (1989-2006). Tese de Doutorado, Universidade de São Paulo.

Cortez, Rafael. 2010. Estratégias partidárias e eleições presidenciais no sistema político brasileiro (19892006). Revista Liberdade e Cidadania, 7: 1-22.

Echegaray, Fabián. 2007. Eleições no Brasil: a caminho de um sistema político moderno. Política \& Sociedade, 10: 13-24.

Fernandes, Antônio Sérgio Araújo. 2002. Path dependency e os estudos históricos comparados. BIB - Revista Brasileira de Informação Bibliográfica, 53: 79-102.

Fleischer, David. 2007. A política de coligações no Brasil - antes e depois da verticalização (1994 e 1998 vs. 2002 e 2006): impactos sobre os partidos. Série Cерpac, 6: 1-21. 
Fleischer, David. 2006. Coligações Eleitorais. In L. Avritzer e F. Anastasia (orgs.), Reforma política no Brasil. Belo Horizonte: UFMG, p. 142-146.

Hall, Peter e Taylor, Rosemary. 2003. As três versões do neo-institucionalismo. Lua Nova, 58: 193-223. http:// dx.doi.org/10.1590/S0102-64452003000100010

Kato, Junko. 1996. Institutions and rationality in politics - three varieties of neo-institutionalists. British Journal of Political Science, 26(4): 553-582. http://dx.doi.org/10.1017/S0007123400007602

Krause, Silvana. 2010. Coligações: o estado e os desafios da arte. In S. Krause, H. Dantas e L. F. Miguel (orgs.), Coligações partidárias na nova democracia brasileira: perfis e tendências. Rio de Janeiro: Konrad-Adenauer-Stiftung; São Paulo: UNESP, p. 9-21.

Krause, Silvana e Schmitt, Rogério (orgs.). 2005. Partidos e coligações eleitorais no Brasil. Rio de Janeiro: Fundação Konrad Adenauer; São Paulo: UNESP.

Lima Júnior, Olavo Brasil de (org.). 1997. O sistema partidário brasileiro: diversidade e tendências (1982-1994). Rio de Janeiro: FGV.

Lima Júnior, Olavo Brasil de. 1983. Partidos políticos brasileiros: a experiência federal e regional: 1945/64. Rio de Janeiro: Graal.

Limongi, Fernando e Cortez, Rafael. 2010. As eleições de 2010 e o quadro partidário. Novos estudos - CEBRAP, 88: 21-37. http://dx.doi. org/10.1590/S0101-33002010000300002

Little, Daniel. 1991. Varieties of social explanation: an introduction to the Philosophy of Social Science. Boulder: Westview.

Mahoney, James. 2005. Combining institutionalisms: liberal reform and critical junctures in Central America. In I. Katznelson e B. Weingast (eds.), Preferences and situations: points of intersection between historical and rational choice institutionalism. New York: Russell Sage Foundation, p. 313-333.

Mahoney, James. 2008. Toward a unified theory of causality. Comparative Political Studies, 41(4-5): 412-436. http://dx.doi.org/10.1177/0010414007313115

Melo, Carlos Ranulfo. 2007. Nem tanto ao mar, nem tanto a terra: elementos para uma análise do sistema partidário brasileiro. In C. R. Melo e M. A. Sáez (orgs.), A democracia brasileira: balanço e perspectivas para o século 21. Belo Horizonte: UFMG, p. 267-302.

Melo, Carlos Ranulfo. 2010. Os partidos e as eleições presidenciais no Brasil. Em Debate, 2(6): 6-11.
Melo, Carlos Ranulfo e Câmara, Rafael. 2012. Estrutura da competição pela presidência e consolidação do sistema partidário no Brasil. Dados - Revista de Ciências Sociais, 55(1): 71-117.

Meneguello, Rachel. 1989. PT: a formação de um partido. Rio de Janeiro: Paz e Terra.

Meneguello, Rachel. 2010. Alguns aspectos da lógica de coalizões partidárias. Textos para Discussão CEPAL/ IPEA, 8: 9-45.

Nascimento, Emerson Oliveira. 2009. Os novos institucionalismos na ciência política contemporânea e o problema da integração teórica. Revista Brasileira de Ciência Política, 1: 95-121.

Nørgaard, Ole. 2001. Democracy, democratization and institutional theory. DEMSTAR Research Report, 4: 3-51.

Pierson, Paul. 2000. Increasing returns, path dependence, and the study of politics. American Political Science Review, 94(2): 251-267. http://dx.doi. org/10.2307/2586011

Pierson, Paul. 2004. Politics in time: history, institutions and social analysis. New Jersey: Princenton.

Pierson, Paul e Skocpol, Theda. 2008. El institucionalismo histórico en la Ciencia Política contemporánea. Revista Uruguaya de Ciencia Política, 17(1): 7-38.

Roma, Celso. 2002. A institucionalização do PSDB entre 1988 a 1999. Revista Brasileira de Ciências Sociais, 17(49): 71-92. http://dx.doi.org/10.1590/ S0102-69092002000200006

Schmitt, Rogério. 2000. Partidos políticos no Brasil (1945-2000). Rio de Janeiro: Jorge Zahar.

Sousa, Vivaldo. 2006. Eleições brasileiras 2006: será que o direito de reeleição para governadores e presidente da República e a verticalização afetam as coligações na disputa de cargos proporcionais? Nashville, VIII Congresso Internacional da Brazilian Studies Association (BRASA).

Steinmo, Sven. 2008. What is historical institucionalism. In D. Della Porta e M. Keating (eds.), Approaches in the Social Sciences. Cambridge: Cambridge University Press, p. 118-139.

Thelen, Kathleen. 1999. Historical institucionalism in comparative politics. Annual Reviews Political Science, 2: 369-404. http://dx.doi.org/10.1146/ annurev.polisci.2.1.369

Van Houten, Pieter. 2009. Multi-level relations in political parties: a delegation approach. Party Politics, 15(2): 137-156. http://dx.doi. org/10.1177/1354068808099978 